\title{
Implementasi Sistem Informasi Sekolah pada Pusat Kegiatan Belajar Mengajar (PKBM) Patrakomala Berbasis Web
}

\author{
Hapsari Widayani*, Hamzah Rabbani, Nicky Rosadi, Windi Megayanti \\ Universitas Indraprasta PGRI \\ *hwidayani@gmail.com
}

\begin{abstract}
Abstrak
Kegiatan pengabdian masyarakat ini bertujuan untuk membantu proses belajar mengajar pelayanan administrasi dan pelaporan keuangan pada pusat kegiatan belajar masyarakat dengan sistem yang terintegrasi dengan baik. Kegiatan pengabdian masyarakat ini akan diadakan pada PKBM Patrakomala Peserta ini adalah pegawai/staf keuangan dan guru-guru PKBM. Metode yang digunakan adalah applied research dan dalam kegiatan ini diawali dengan melakukan proses wawancara, observasi, dan pengamatan mengenai administrasi sekolah dan keuangan mitra, lalu mengumpulkan hasil wawancara dan mengenalkan hasil sistem informasi (transfer knowledge) tersebut ke mitra. Adapun produk yang dihasilkan berupa implementasi sistem informasi administrasi sekolah beserta keuangan berbasis web, user interface yang didesain menarik, dan terstruktur dengan baik. Diharapkan implementasi sistem ini dapat dipergunakan dengan baik dan dapat dikembangkan lebih lanjut. Kata kunci: sistem informasi keuangan, sistem informasi administrasi, web-based, entity relationship diagram
\end{abstract}

\section{Implementation of School Information System Web-Based at PKBM Patrakomala}

\begin{abstract}
This community service activity aims to assist the teach and learn process, administrative services, and financial reporting at PKBM. This community service activity has been held at PKBM Patrakomala. These participants are financial staff and teachers. The method used is an applied research and the activity begins with a process of interview, observation, and observations about the school administration and finance of partner, and then collect the results of interviews and transfer knowledge to partner. The products are implementation of administrative system, web-based finance system, user interface that attractive and well-structured. Hoped that the implementation of this system can be used properly and developed further.

Keywords: financial information system, administrative information system, web-based, entity relationship diagram
\end{abstract}

\section{PENDAHULUAN}

Dewasa ini, pendidikan adalah suatu hal terpenting dalam kehidupan sehari-hari. Pentingnya sebuah pendidikan menyebabkan semua kalangan baik anak-anak hingga dewasa berhak mendapatkannya. Meningkatnya kesadaran masyarakat terhadap pentingnya pendidikan, membuka mata kita bahwa pendidikan tidak hanya dapat dimaknai sebagai sekolah saja. Ia membutuhkan pengertian secara luas, bermakna, dan memberikan faedah bagi terbentuknya tatanan masyarakat, yang tidak hanya cerdas tapi juga berkarakter luhur (Sahlan,2012). Pendidikan pertama kali yang kita dapatkan adalah pada lingkungan keluarga. Keluarga berperan penting dalam membentuk karakter diri pada setiap anak. Pendidikan yang kedua atau setelah keluarga adalah sekolah. Lingkungan sekolah memberi peranan penting dalam mengajarkan anak perihal pendidikan formal dan non formal. Pendidikan formal menurut Undang-Undang Nomor 20 tahun 2003 adalah jalur pendidikan yang terstruktur dan berjenjang yang terdiri atas pendidikan dasar, menengah, dan tinggi. Sedangkan pendidikan non formal adalah setiap kesempatan di mana terdapat komunikasi yang terarah di luar sekolah dan seseorang memperoleh informasi, pengetahuan, latihan maupun bimbingan sesuai dengan tingkat usia dan kebutuhan hidup dengan jutaan mengembangkan tingkat keterampilan, sikap, dan nilai-nilai yang memungkinkan baginya menjadi peserta-peserta yang efisien dan efektif 
dalam lingkungan keluarga, pekerjaan, bahkan lingkungan masyarakat, dan negaranya (Soelaman, Joesoef 1992:51).

Salah satu bentuk pendidikan non formal adalah pendidikan kesetaraan paket A,B, dan C pada pusat kegiatan belajar mengajar (PKBM), keaksaraan, pemberdayaan perempuan, pendidikan usia dini (PAUD), dan kegiatan ekstrakurikuler yang dilakukan di setiap sekolah. Pusat kegiatan belajar mengajar (PKBM) adalah sebuah lembaga pendidikan yang diselenggarakan di luar sistem pendidikan formal, diarahkan untuk masyarakat pedesaan dan perkotaan dengan dikelola oleh masyarakat itu sendiri serta memberi kesempatan kepada mereka untuk mengembangkan berbagai model pembelajaran dengan tujuan mengembangkan kemampuan dan keterampilan masyarakat agar mampu meningkatkan kualitas hidupnya (Kamal, 2009:85). Pada tahun 2017 jumlah PKBM yang dikelola oleh swasta di kota Bandung sebanyak 111 sekolah dan di kota Depok sebanyak 48 sekolah (Kemendikbud, 2018). Pendidikan non formal yang disediakan pada sekolah PKBM adalah paket kesetaraan A, B, dan C, serta keaksaraan. Paket A adalah pendidikan setara SD, Paket B adalah pendidikan setara SMP, dan Paket $\mathrm{C}$ adalah pendidikan setara SMA/SMK.

Sekolah non formal ini masih memiliki banyak kekurangan yaitu belum menggunakan sistem yang terintegrasi dengan baik. Sistem manual ini menyebabkan kualitas informasi yang dihasilkan belum cukup akurat, proses pelayanannya kurang cepat, dan pencatatan data berulang (double entry).

Untuk mengatasi permasalahan yang telah disebutkan di atas maka solusi yang ditawarkan dalam kegiatan pengabdian masyarakat ini adalah membuat sistem informasi sekolah pada pusat kegiatan belajar mengajar (PKBM) dan di transfer ilmunya kepada staff dan guru-guru PKBM melalui sebuah training. Tujuan dari kegiatan ini yaitu dapat membantu proses belajar mengajar, pelayanan administrasi, dan pelaporan keuangan agar lebih tertib dan akurat.

\section{METODE PELAKSANAAN}

Tempat kegiatan pengabdian masyarakat yaitu pada Pusat Kegiatan Belajar Mengajar (PKBM) Patrakomala yang beralamat di Jalan Nagrog III No.106 RT 1 RW 09 Pasarjati, Ujungberung - Bandung. Waktu pelaksanaan kegiatan yaitu minggu pertama (1) bulan Juli 2018 hingga Desember 2018. Peserta dalam kegiatan pengabdian masyarakat ini adalah guru dan pegawai PKBM. Berjumlah 10 staf dan 3 guru.

Metode pelaksanaan dalam kegiatan ini, yaitu:

a) Pengamatan atau Observasi

Melakukan pengamatan terhadap kegiatan yang terjadi di PKBM Patrakomala dan PKBM Hiama terutama pada bagian administrasi dan bagian keuangan.

b) Wawancara

Mengajukan sejumlah pertanyaan yang berhubungan dengan proses dan prosedur administrasi pelayanan sekolah terpadu pada mitra.

c) Sosialisasi

Tim pelaksana pengabdian masyarakat melakukan sosialisasi bagi pegawai dan guru-guru agar dapat mengimplementasikan sebuah sistem informasi sekolah terpadu yang telah dibuat dengan baik. 
Vol. 2, No. 2,

July, 2021,

pp. 192-206

e-ISSN:

2722-2004

Implementation

of School

Information

System

Web-Based at

PKBM

Patrakomala

H. Widayani,

H. Rabbani,

N. Rosadi,

W. Megayanti.

d) Hasil Akhir

Hasil akhir yang diberikan adalah berupa publikasi ilmiah di jurnal/prosiding, sistem yang terintegrasi, dan manual book. berikut:

Langkah-langkah dari kegiatan pengabdian masyarakat ini yaitu sebagai

1. Melakukan kunjungan ke lokasi pengabdian masyarakat untuk survei tempat dan data.

2. Melakukan kerja sama dengan pihak mitra yang telah disepakati bersama.

3. Mengadakan perjanjian dengan mitra untuk melakukan wawancara, observasi, dan pengamatan mengenai penerimaan dan pengeluaran kas.

4. Mengumpulkan hasil wawancara, observasi, dan pengamatan untuk di telaah bersama oleh tim.

5. Membuat planning sistem yang akan dibutuhkan sesuai fungsional dan non fungsional di PKBM.

6. Menganalisis sistem yang akan dibutuhkan sesuai fungsional dan non fungsional di PKBM.

7. Merancang desain sistem yang akan dibutuhkan sesuai fungsional dan non fungsional di PKBM.

8. Implementasi sistem informasi sekolah terpadu

9. Mengenalkan hasil sistem informasi sekolah terpadu (transfer knowledge) ke mitra PKBM.

\section{HASIL DAN PEMBAHASAN}

\section{Entity Relationship Diagram}

Entity Relationship Diagram (ERD) dari sistem informasi sekolah terpadu pada pusat kegiatan belajar mengajar terdiri dari sembilan proses. Proses yang pertama adalah pendaftaran siswa baru yang dilakukan oleh orang tua siswa atau siswa itu sendiri. Proses pertama ini entitas awalnya yaitu siswa baru dan primary key adalah nama lengkap. Output-nya adalah bagian dokumen pendaftaran. Proses kedua adalah proses pembayaran pendaftaran siswa baru. Entitas awalnya adalah siswa baru dan output-nya adalah keuangan. Primary key proses kedua adalah tanggal lahir dan output yang dihasilkan adalah bagian keuangan. Proses ketiga adalah proses pembayaran SPP dan ujian. Entitas awalnya adalah siswa PKBM dan output-nya adalah keuangan. Primary key-nya adalah nomor telepon. Proses keempat adalah proses pembelian inventory di mana entitas awalnya adalah bagian keuangan dan primary key adalah NIK/NIP serta output yang dihasilkan adalah dokumen akuntansi.

Proses kelima adalah proses pembayaran operasional di mana entitas awalnya adalah bagian keuangan dan primary key adalah jabatan serta output yang dihasilkan adalah dokumen akuntansi. Proses keenam adalah proses pembayaran gaji di mana entitas awalnya adalah bagian keuangan dan primary key adalah status 
serta output yang dihasilkan adalah dokumen akuntansi. Proses ketujuh adalah proses input dan approval jadwal mata pelajaran dan list ijazah di mana entitas awalnya adalah bagian tata usaha dan primary key adalah nama lengkap serta output yang dihasilkan adalah kepala sekolah. Proses kedelapan adalah proses pembuatan laporan keuangan di mana entitas awalnya adalah bagian tata usaha dan primary key adalah NIK/NIP serta output yang dihasilkan adalah kepala sekolah karena proses ini harus membutuhkan pemeriksaan dan persetujuan dari kepala sekolah. Adapun Entity Relationship Diagram tersebut dapat dilihat pada gambar di bawah ini:

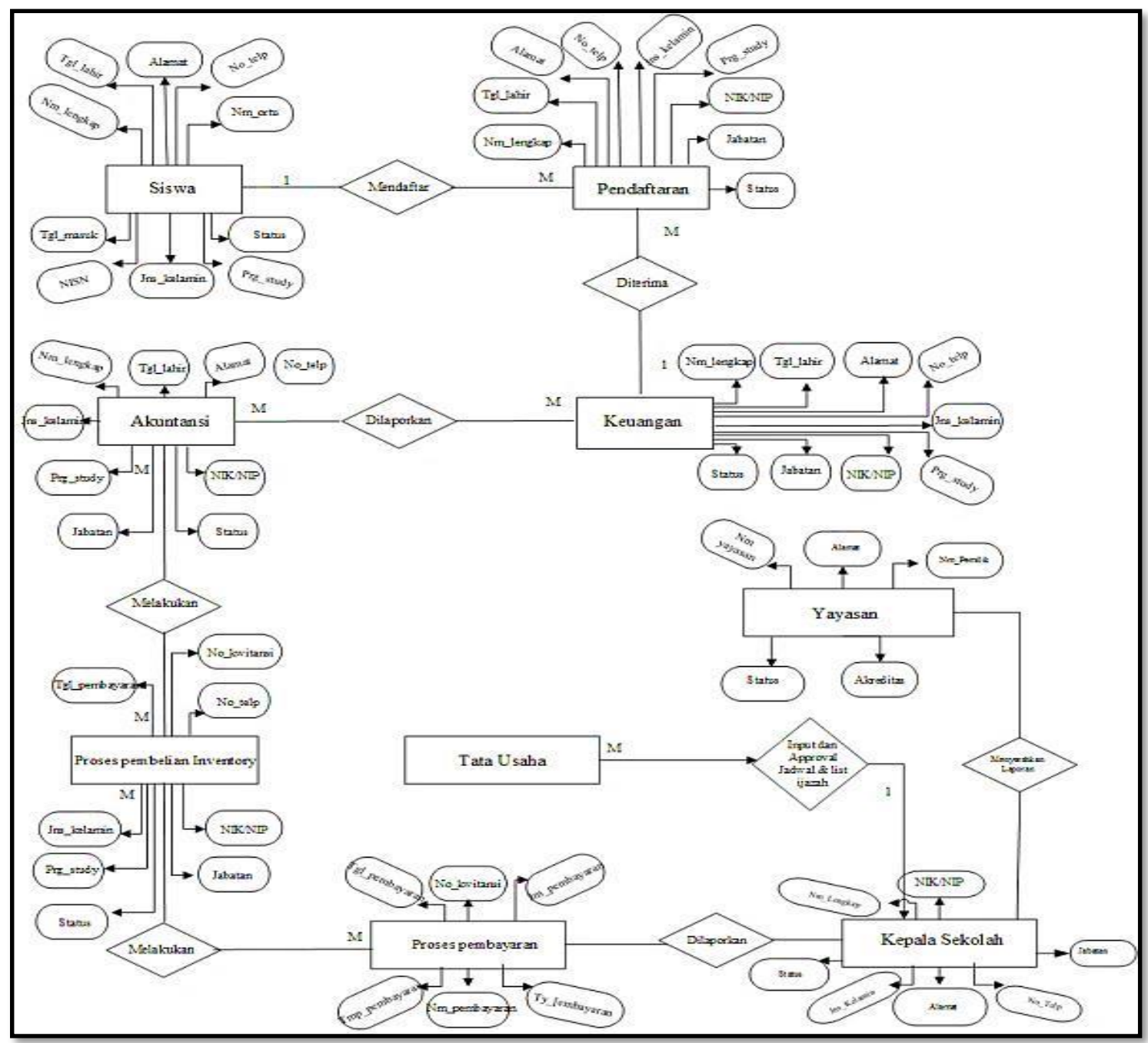

Sumber: Diolah (2021)

Gambar 1. Entity Relationship Diagram Sistem Informasi Sekolah Terpadu pada Pusat Kegiatan Belajar Mengajar (PKBM) di Jawa Barat

Program pengabdian masyarakat ini menghasilkan beberapa luaran atau output yaitu sistem informasi sekolah berbasis web, output yang dihasilkan sistem informasi sekolah adalah adanya tampilan depan (front end) dan belakang (back end). Metode pengembangan aliran data yang digunakan adalah data flow diagram dan entity relationship diagram. Adapun hasil tampilan sistem yang dihasilkan sebagai berikut:
KANGMAS is a journal published by Neolectura, issued three times in one year. KANGMAS is a scientific publication media in the form of conceptual paper and field research related to social service work. It is hoped that KANGMAS can become a media for academics and researchers to publish their social service work and become a reference source for the development of social and humanity.

Our focus: Social Service

Our Scope:

Humanities,

Education,

Management,

History,

Economics,

Linguistics,

Literature,

Religion,

Politics,

Sociology,

Anthropology,

and other social service works. 
KANGMAS: Karya Ilmiah Pengabdian Masyarakat, Vol. 2 No. 2, July 2021 - 196

http://journal.neolectura.com/index.php/kangmas

\section{Home Page}

Vol. 2, No. 2, July, 2021, pp. 192-206

e-ISSN:

2722-2004

Implementation of School Information System

Web-Based at PKBM

Patrakomala

H. Widayani, H. Rabbani, N. Rosadi, W. Megayanti.

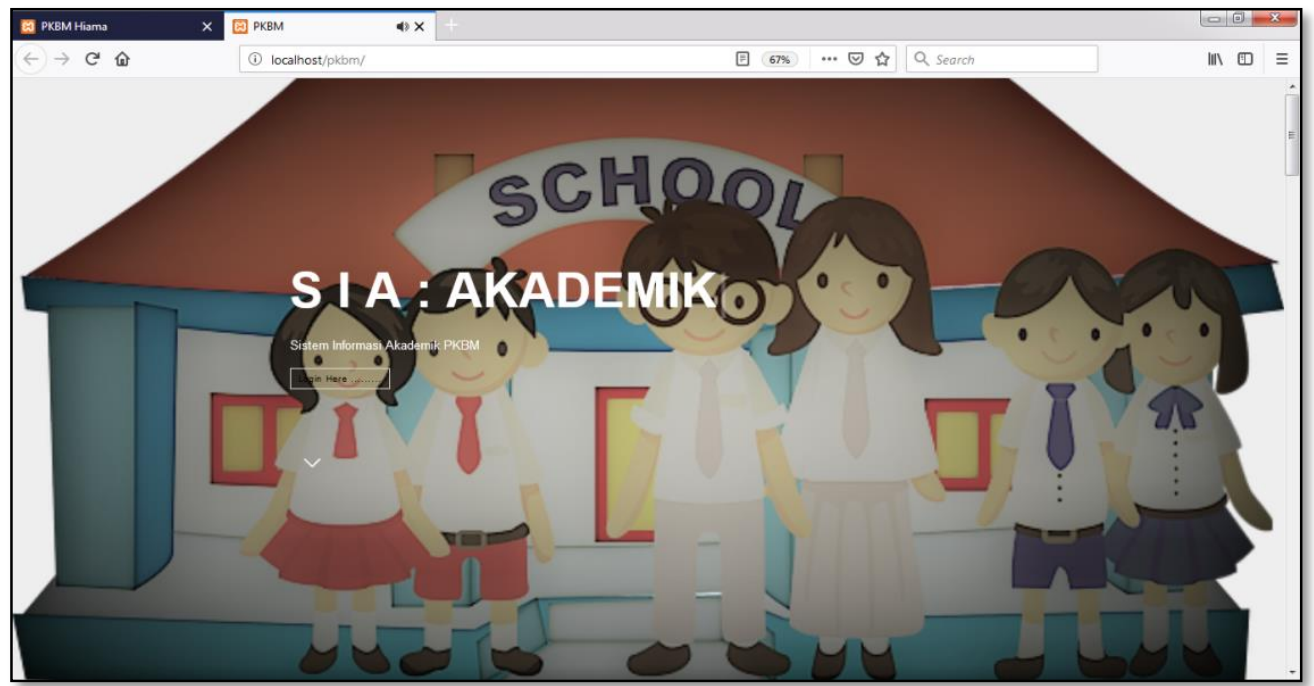

Sumber: Diolah (2021)

Gambar 2. Menu Home Page

\section{Menu Profile}

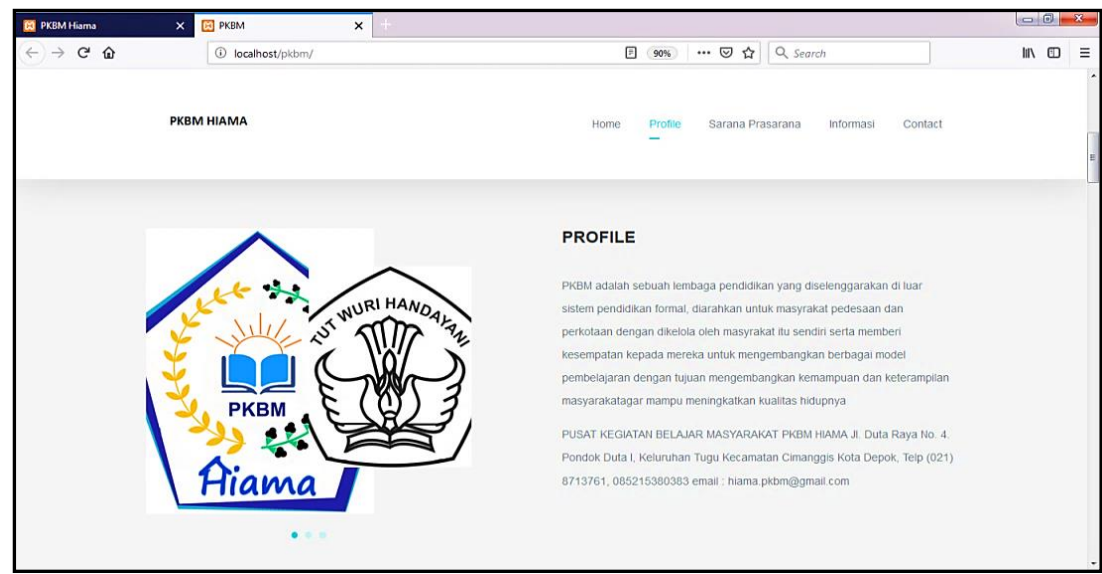

Sumber: Diolah (2021)

Gambar 3. Menu Profile

\section{Menu Sarana dan Prasarana}

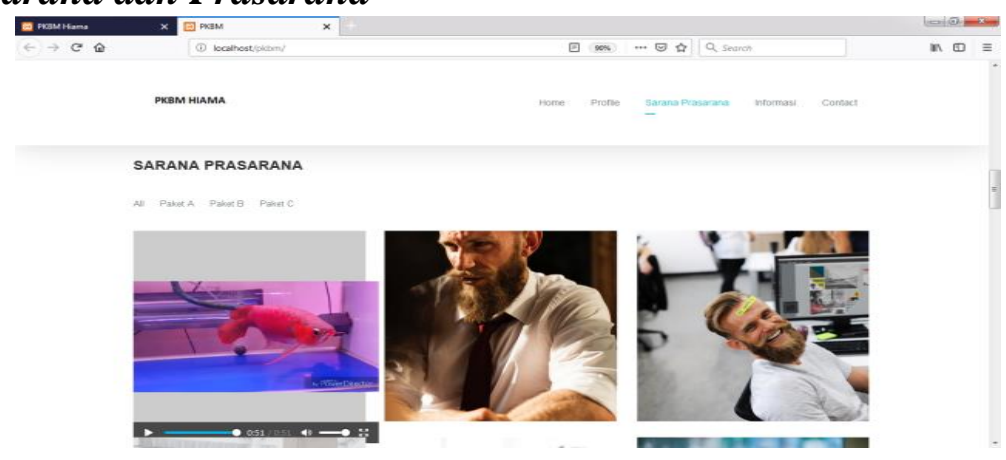

Sumber: Data diolah (2021)

Gambar 4. Menu Sarana dan Prasarana 
KANGMAS: Karya Ilmiah Pengabdian Masyarakat, Vol. 2 No. 2, July 2021 - 197

http://journal.neolectura.com/index.php/kangmas

\section{Menu Informasi}

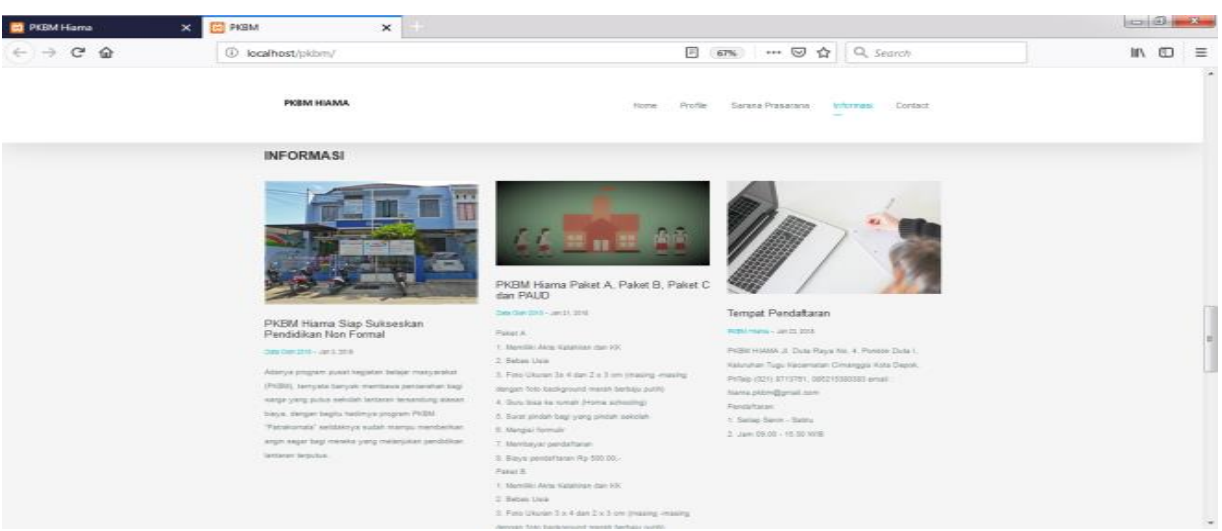

Sumber: Diolah (2021)

Gambar 5. Menu Informasi

\section{Buku Tamu}

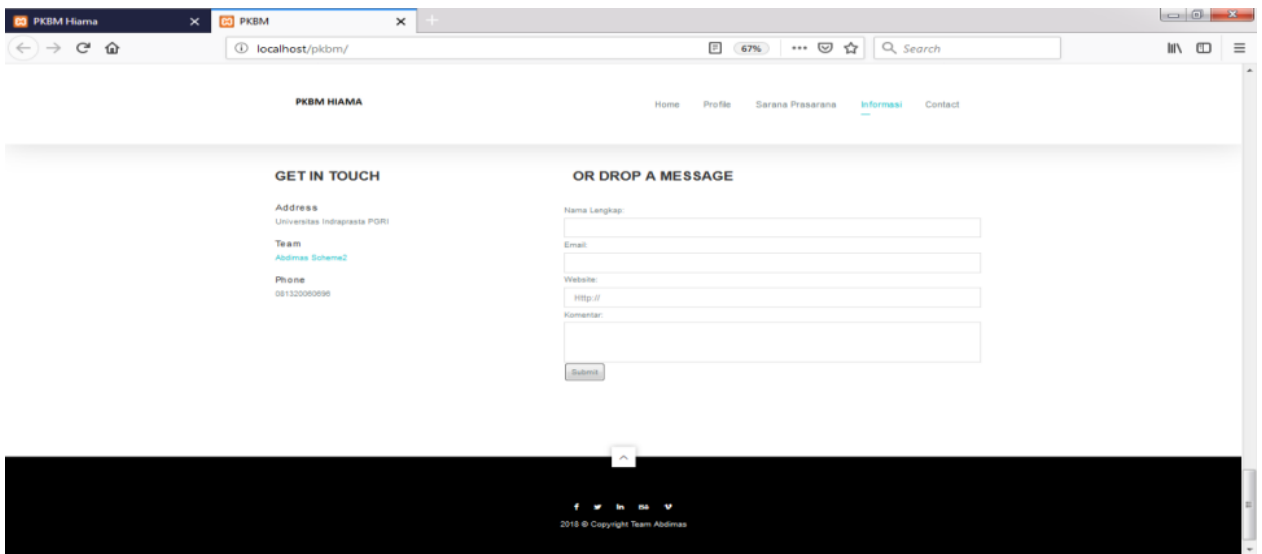

Our focus: Social Service

Our Scope:

Humanities,

Education,

Management,

History,

Economics,

Linguistics,

Literature,

Religion,

Politics,

Sociology,

Anthropology,

and other social service works.

Sumber: Diolah (2021)

Gambar 6. Menu Buku Tamu

\section{Menu Login}

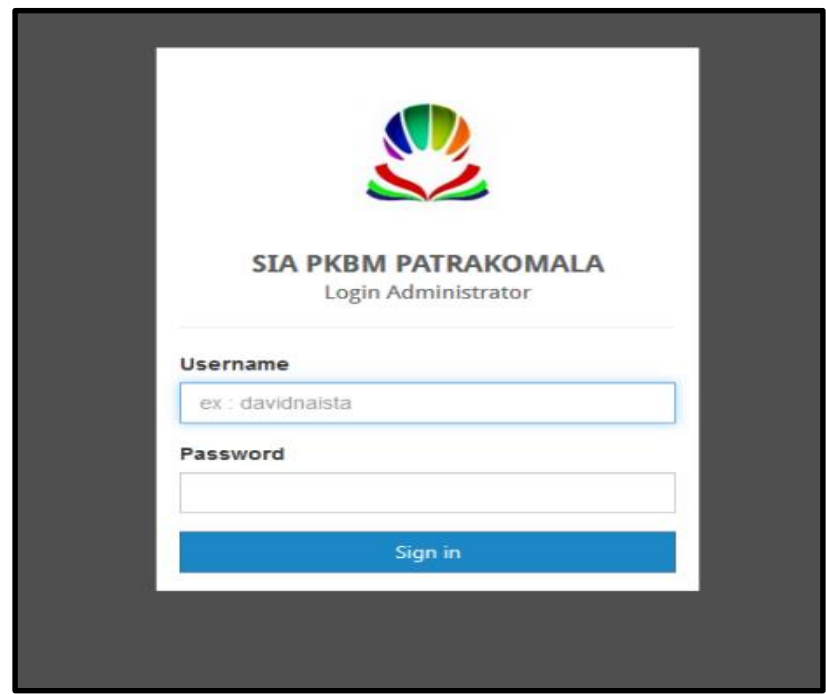


KANGMAS: Karya Ilmiah Pengabdian Masyarakat, Vol. 2 No. 2, July 2021 - 198

http://journal.neolectura.com/index.php/kangmas

Vol. 2, No. 2,

July, 2021,

pp. 192-206

e-ISSN:

2722-2004

Implementation of School

Information

\section{System}

Web-Based at

\section{PKBM}

Patrakomala

\section{H. Widayani,}

H. Rabbani,

N. Rosadi,

W. Megayanti.
Sumber : Diolah (2021)

\section{Gambar 7. Menu Login}

\section{Tampilan Halaman Belakang}

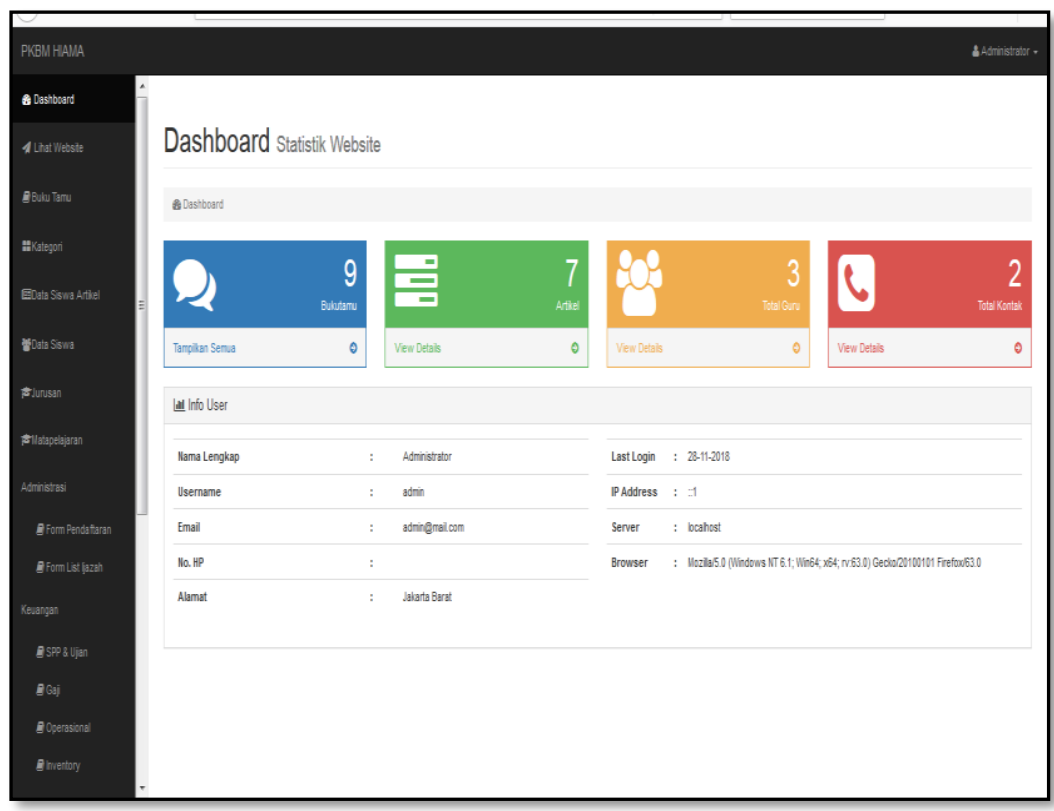

Sumber: Diolah (2021)

Gambar 8. Tampilan Halaman Belakang

\section{Menu Kategori}

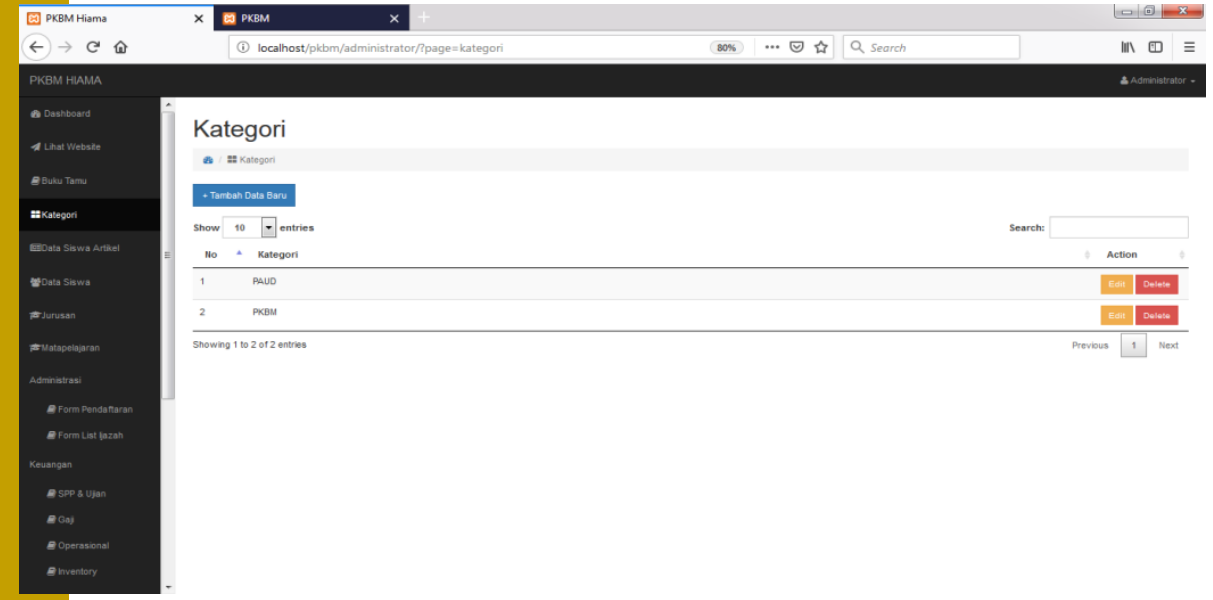

Sumber: Diolah (2021) 
KANGMAS: Karya Ilmiah Pengabdian Masyarakat, Vol. 2 No. 2, July 2021 - 199

http://journal.neolectura.com/index.php/kangmas

Gambar 9. Menu Kategori

\section{Menu Siswa}

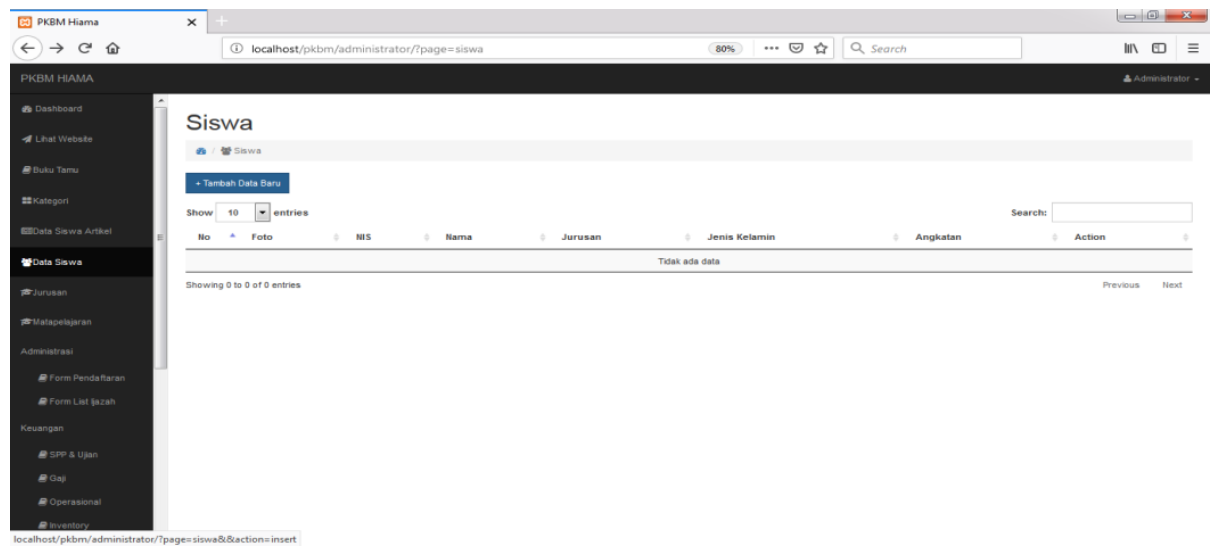

Sumber: Diolah (2021)

Gambar 10. Menu siswa

\section{Menu Mata Pelajaran}

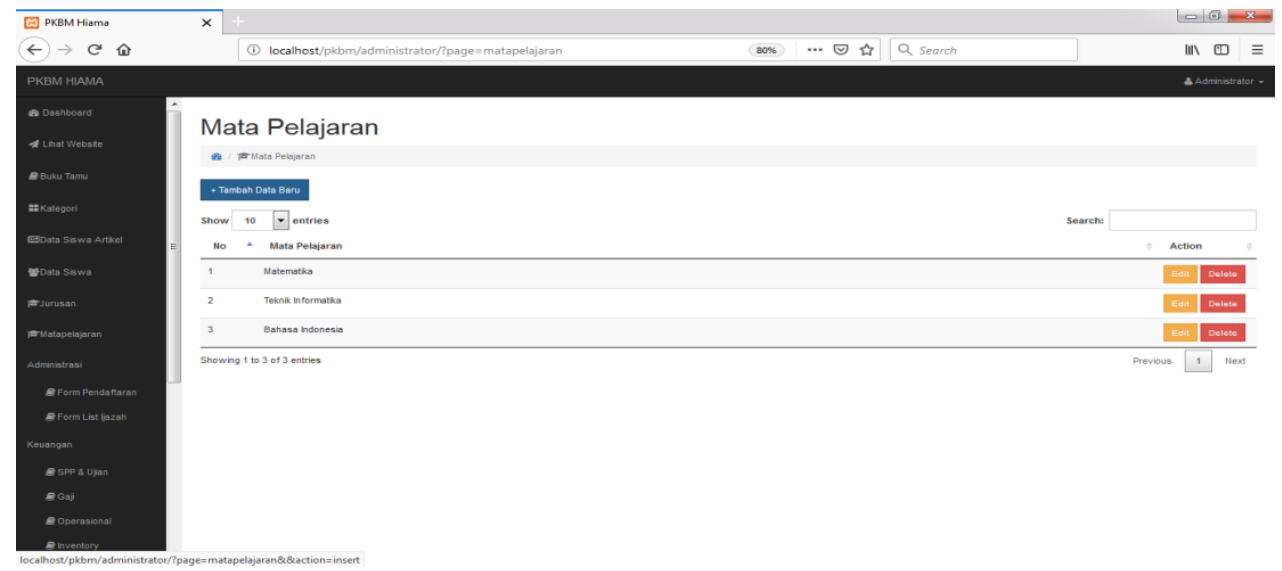

Sumber: Diolah (2021)

\section{Menu List Ijazah}

Gambar 11. Menu Mata Pelajaran

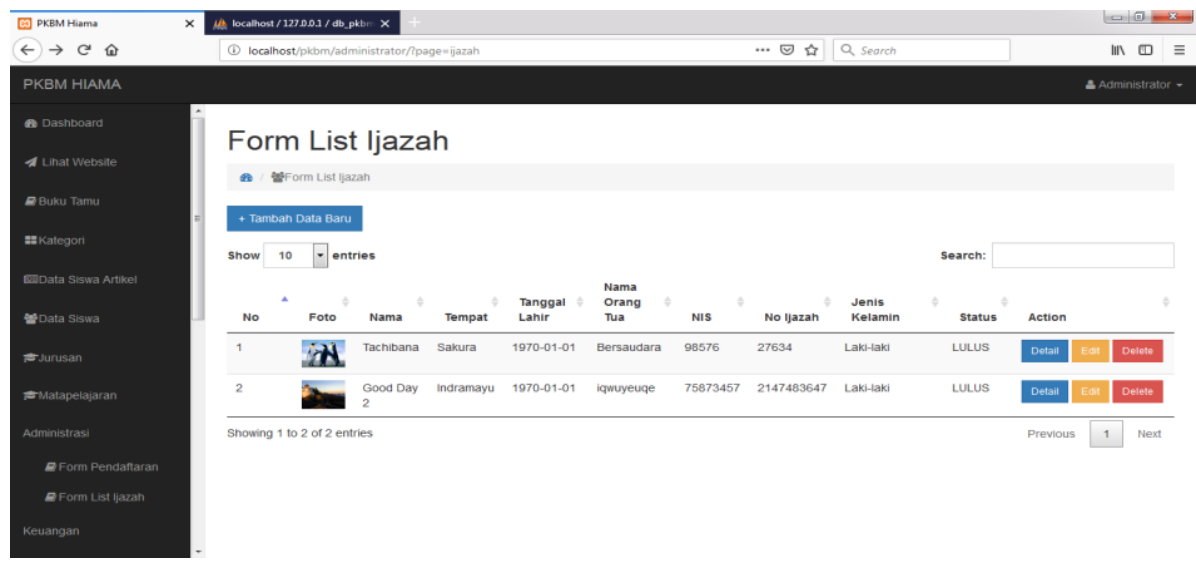

Sumber: Diolah (2021)

Gambar 12. Menu list Ijazah 
KANGMAS: Karya Ilmiah Pengabdian Masyarakat, Vol. 2 No. 2, July 2021 - 200

http://journal.neolectura.com/index.php/kangmas

Vol. 2, No. 2,

July, 2021,

pp. 192-206

e-ISSN:

2722-2004

Implementation of School

Information

System

Web-Based at

PKBM

Patrakomala

H. Widayani,

H. Rabbani,

N. Rosadi,

W. Megayanti.

\section{Menu SPP \& Ujian}

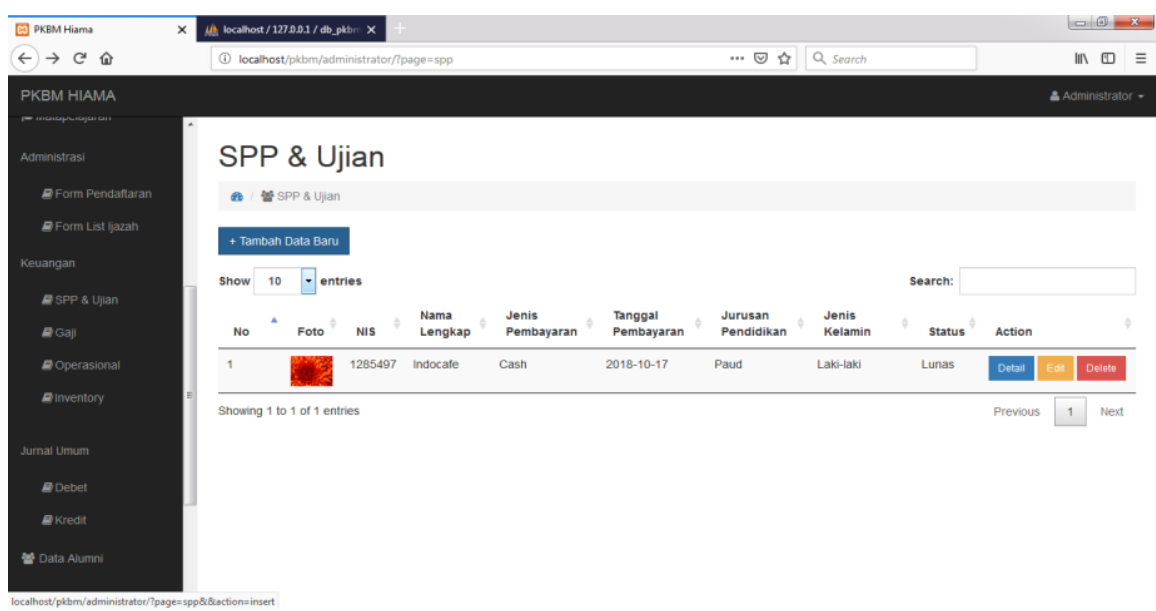

Sumber: Diolah (2021)

Gambar 13. Menu SPP \& Ujian

Menu Gaji

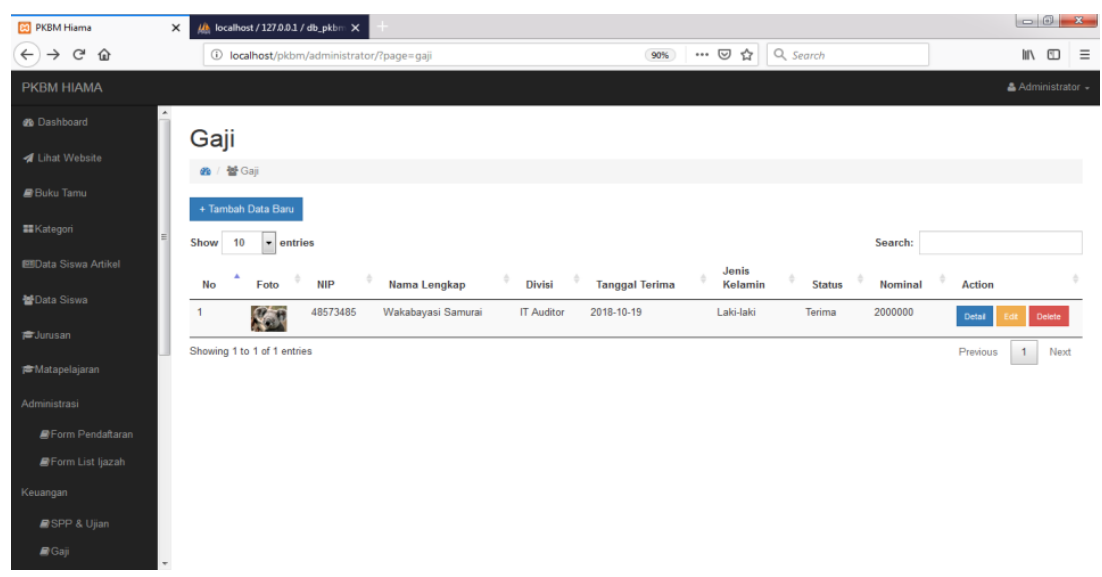

Sumber: Diolah (2021)

Menu Operasional

Gambar 14. Menu Gaji

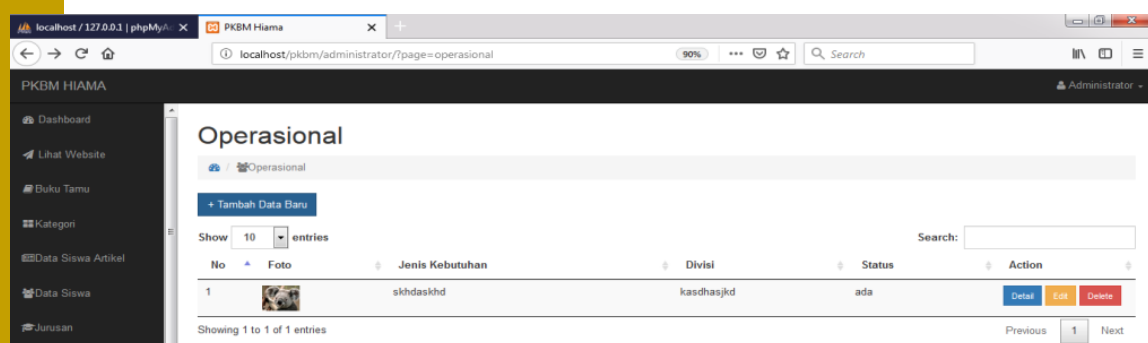

Gambar 15. Menu Operasional

https://doi.org/10.37010/kangmas.v2i2.344 
KANGMAS: Karya Ilmiah Pengabdian Masyarakat, Vol. 2 No. 2, July 2021 - 201

http://journal.neolectura.com/index.php/kangmas

\section{Menu Inventory}

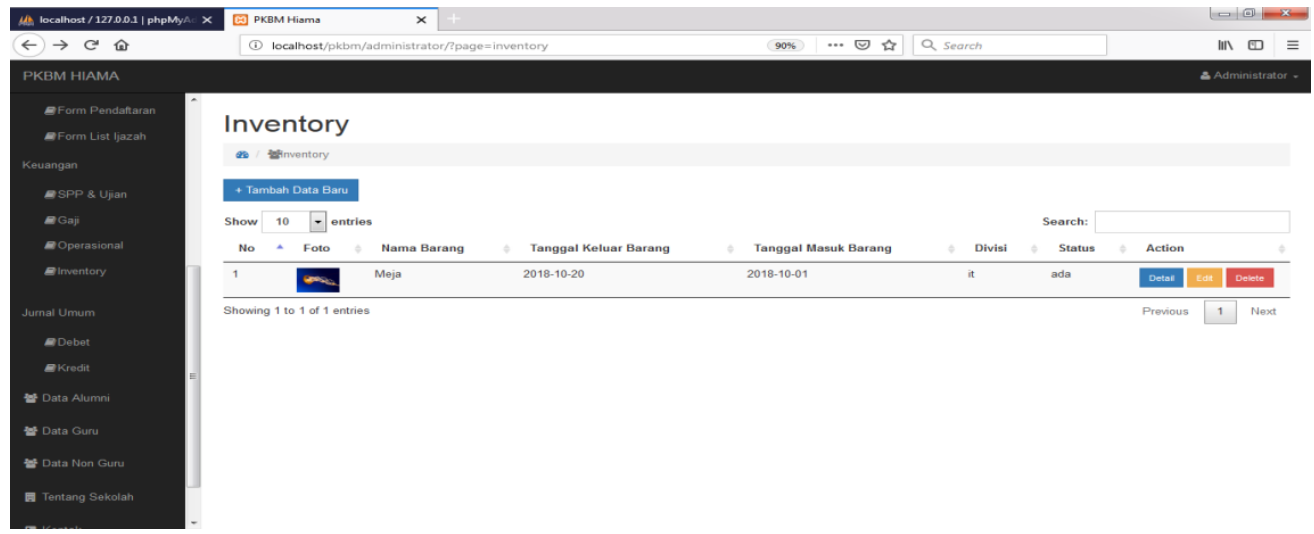

Sumber: Diolah (2021)

Gambar 16. Menu Inventory

\section{Menu Debet dan Kredit}
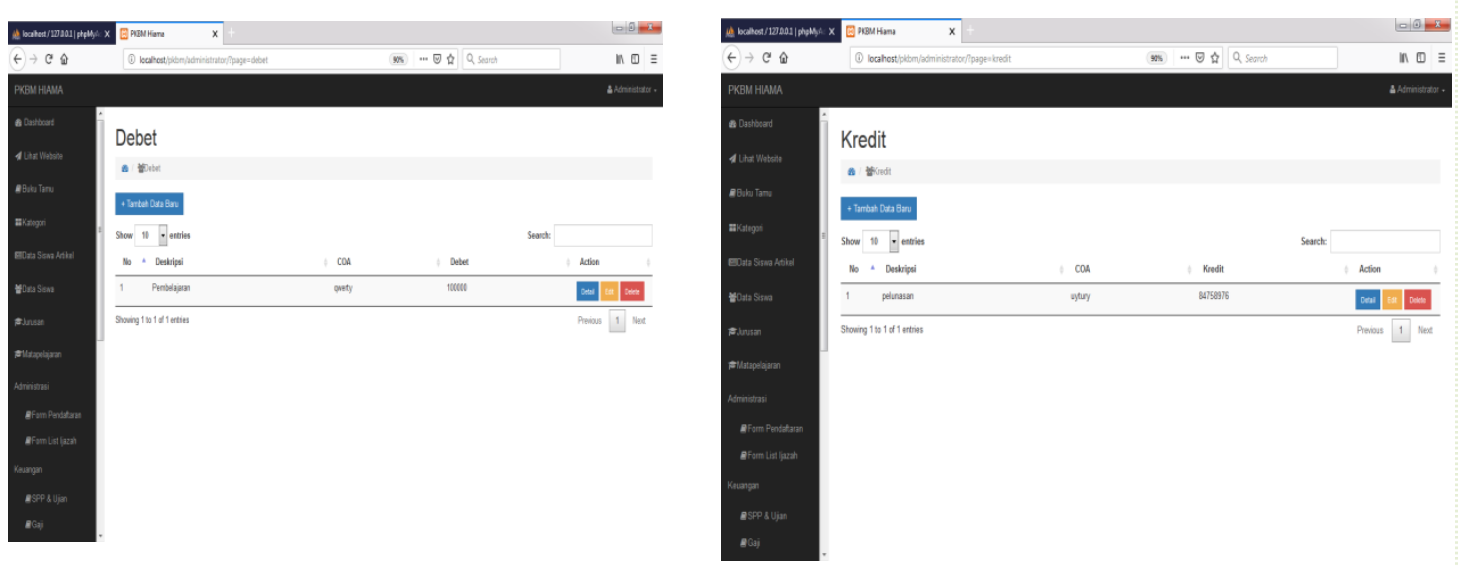

Our focus: Social Service urnal published by Neolectura, issued three times in one year. KANGMAS is a scientific publication media in the form of conceptual paper and field research related to social service work. It is hoped that KANGMAS can become a media for academics and researchers to publish their social service work and become a reference source for the development of social and humanity.

Sumber: Diolah (2021)

Gambar 17. Menu Debet dan Kredit

\section{Menu Alumni}

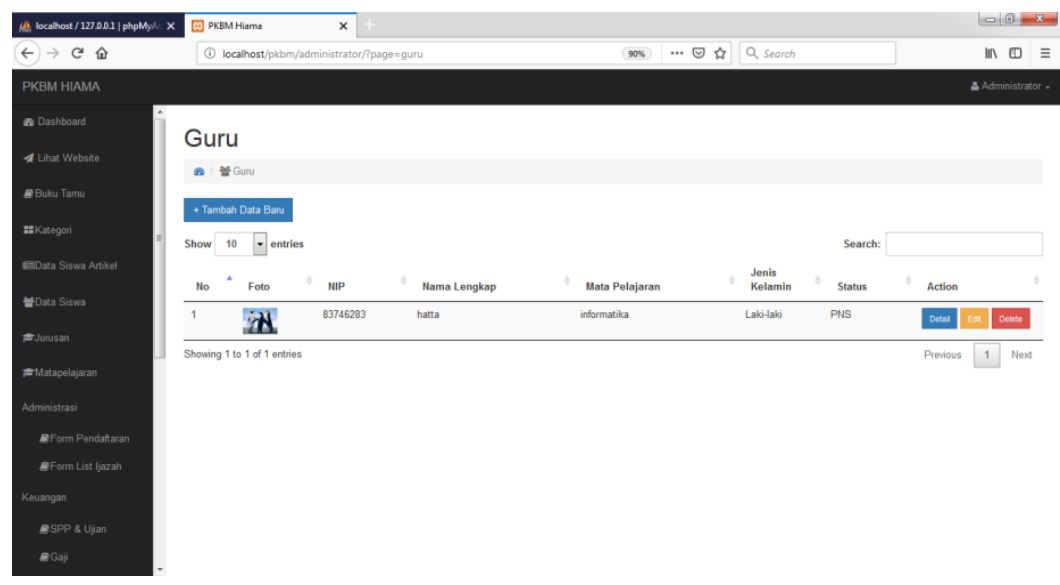

Sumber: Diolah (2021)

Gambar 18. Menu Alumni 
KANGMAS: Karya Ilmiah Pengabdian Masyarakat, Vol. 2 No. 2, July 2021 - 202

http://journal.neolectura.com/index.php/kangmas

Vol. 2, No. 2,

July, 2021,

pp. 192-206

e-ISSN:

2722-2004

Implementation of School

Information

System

Web-Based at

\section{PKBM}

Patrakomala

H. Widayani,

H. Rabbani,

N. Rosadi,

W. Megayanti.

\section{Menu Guru}

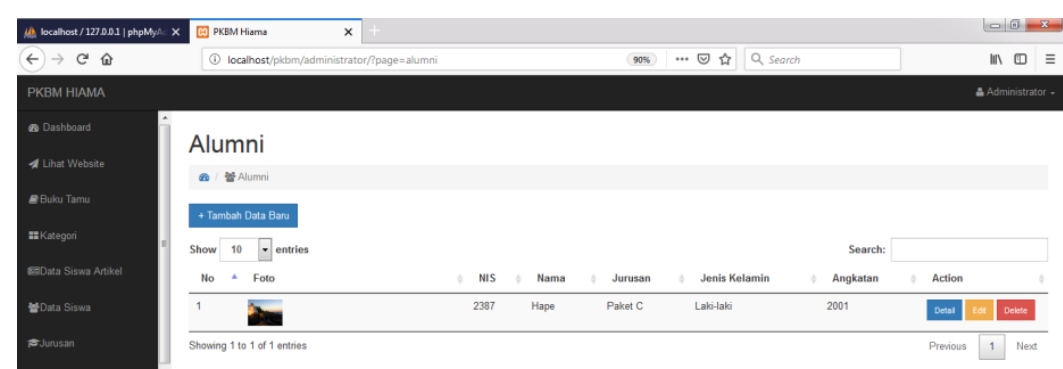

Sumber: Diolah (2021)

Gambar 19. Menu Guru

Menu Non-Guru

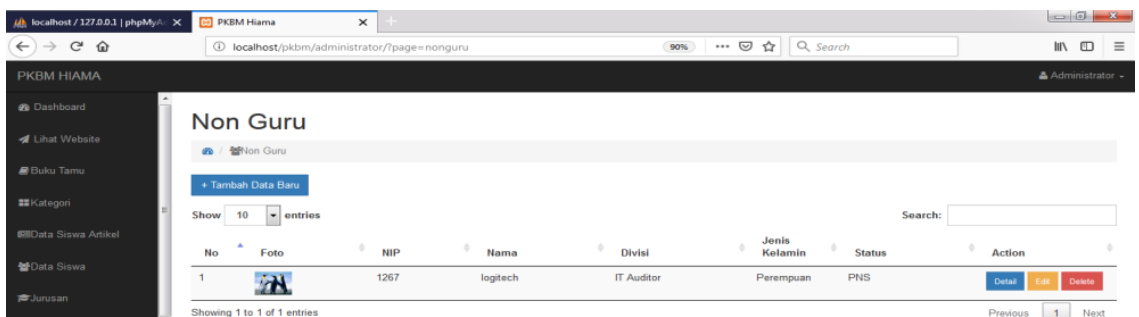

Gambar 20. Menu Non-Guru

Sumber: Diolah (2021)

\section{Menu Tentang Sekolah}

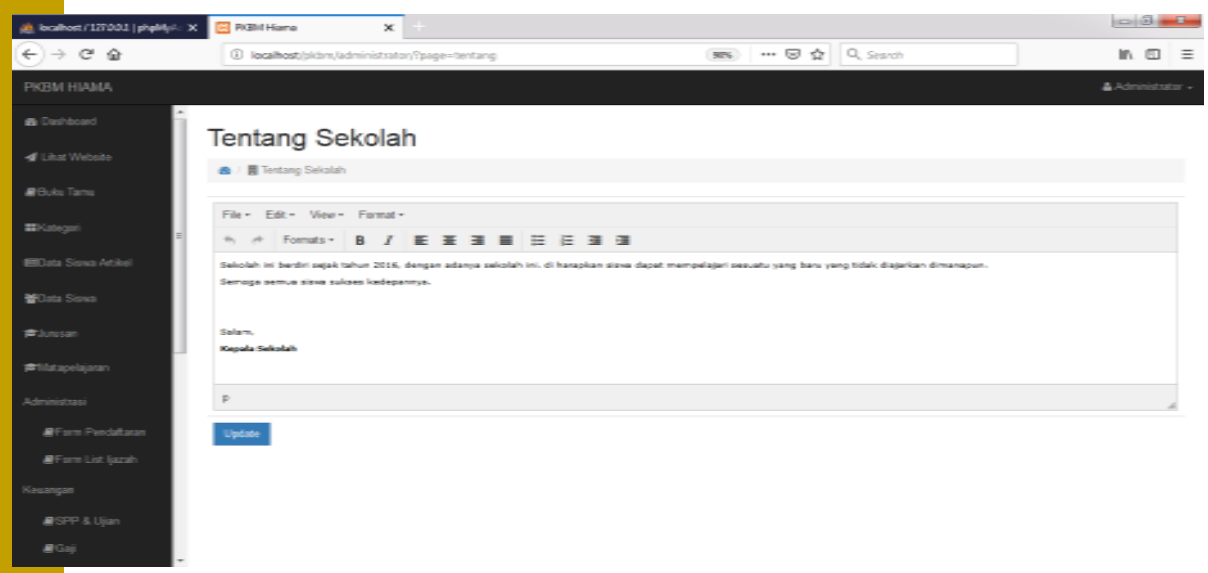

Sumber: Diolah (2021) 
KANGMAS: Karya Ilmiah Pengabdian Masyarakat, Vol. 2 No. 2, July 2021 - 203

http://journal.neolectura.com/index.php/kangmas

\section{Gambar 21. Menu Tentang Sekolah}

\section{Menu Manajemen User}

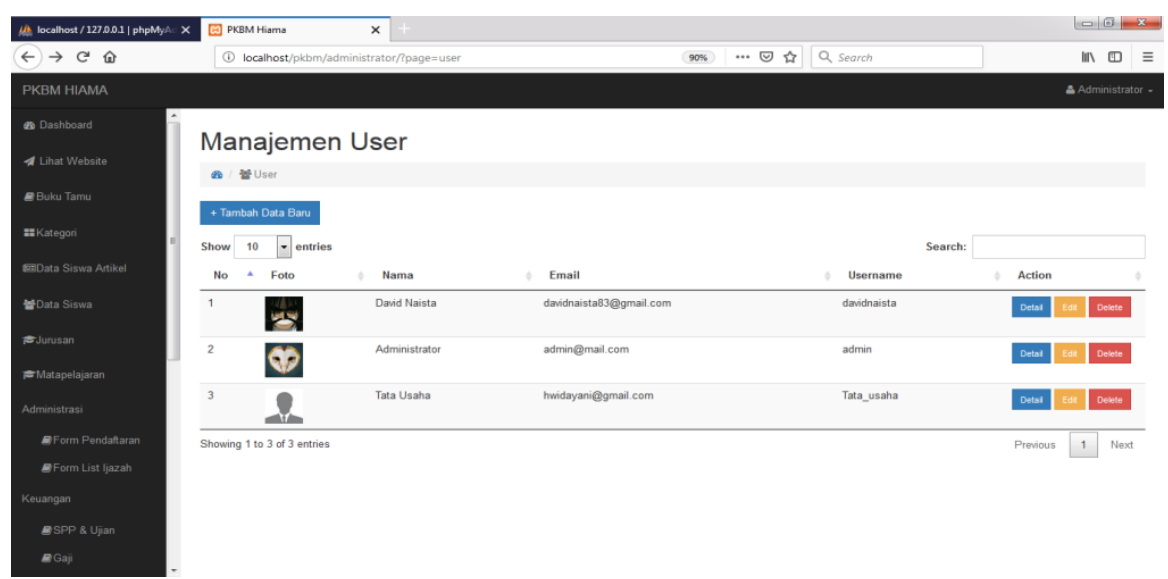

Sumber: Diolah (2021)

Gambar 22. Menu Manajemen User

Tampilan di atas menggambarkan sebuah sistem informasi sekolah yang mana sistem ini dapat menampung data yang akan di-input oleh administrator dan tersimpan dengan baik.

Di sisi lain, dengan adanya sebuah sistem informasi sekolah tersebut terlihat perbedaan yang signifikan pada pelayanan administrasi dan keuangan. Adapun analisis yang digunakan untuk menunjukkan perbedaan tersebut yaitu penggunaan analisis PIECES (Performance, Information, Economy, Control, Efficiency, Service). Analisis PIECES ini adalah analisis yang menilai bagaimana kinerja, informasi, kebutuhan dari segi ekonomi, pengawasan, efisiensi terhadap sistem, dan pelayanan terhadap pengembangan sistem itu berjalan (Widayani, 2016). Adapun analisis PIECES pada sistem informasi sekolah yang lama dan usulan dari team pengabdian masyarakat adalah sebagai berikut: 
Vol. 2, No. 2, July, 2021, pp. 192-206

Implementation of School Information System Web-Based at

\section{PKBM}

Patrakomala

H. Widayani, H. Rabbani, N. Rosadi. W. Megayanti.

\section{Tabel 1. Analisis PIECES}

\begin{tabular}{|c|c|c|c|}
\hline No & Kategori & $\begin{array}{l}\text { Sistem Informasi Sekolah pada } \\
\text { PKBM Patrakomala }\end{array}$ & $\begin{array}{c}\text { Sistem Informasi Sekolah pada PKBM } \\
\text { Yang Diusulkan }\end{array}$ \\
\hline 1 & Performance & $\begin{array}{l}\text { - Pelayanan kepada siswa dan } \\
\text { orang tua saat melakukan input } \\
\text { data pendaftaran serta } \\
\text { pembayaran keuangan (SPP dan } \\
\text { Ijazah) membutuhkan waktu } \\
\text { sekitar } \mathbf{1 5} \text { menit. Hal ini } \\
\text { disebabkan bagian pendaftaran }\end{array}$ & $\begin{array}{l}\text { - Pelayanan pendaftaran dan keuangan } \\
\text { hanya membutuhkan waktu sekitar 7- } \\
\mathbf{1 0} \text { menit. Ini disebabkan karena } \\
\text { bagian pendaftaran dan keuangan } \\
\text { sudah menggunakan sistem database } \\
\text { untuk mencari data pendaftaran dan } \\
\text { keuangan. }\end{array}$ \\
\hline
\end{tabular}

- Pembuatan laporan keuangan pada sekolah ini sudah menggunakan aplikasi yang telah dirancang oleh penulis. Waktu yang dibutuhkan dalam pembuatan laporan keuangan sekitar $\mathbf{3}$ jam.

- Pembuatan laporan keuangan pada sekolah ini masih menggunakan cara manual yaitu di rekap pada buku pembukuan harian dan bulanan serta dihitung dengan menggunakan kalkulator.

2 Information Informasi mengenai pelayanan sekolah berupa hardcopy dan masih diberikan informasi melalui cara manual (face to face) dengan petugas pendaftaran.

3 Economy

Pembuatan laporan pendaftaran dan keuangan membutuhkan beberapa perlengkapan yaitu alat hitung (kalkulator), buku, dan alat tulis kantor lainnya. Hal ini menyebabkan biaya operasional yang cukup banyak

- Sekolah ini belum melakukan pembagian tugas dan tanggung jawab yang merata sehingga antara satu bagian dengan bagian lainnya tidak terlihat secara jelas tanggung jawab masing - masing dari pekerjaannya.

- Pencatatan yang dilakukan masih manual dan disimpan dalam bentuk arsip - arsip maka tingkat keamanannya menjadi kurang baik sehingga membutuhkan control yang lebih.
Informasi mengenai seluruh pelayanan sekolah di input secara tersistem dan dokumen yang dihasilkan berupa softcopy. Disisi lain, informasi mengenai sekolah dilakukan secara tersistem sehingga para orang tua hanya perlu membaca semua informasi melalui aplikasi sekolah. Jika informasi kurang dipahami, pihak sekolah membuka call center bagi orang tua dan siswa/i.

Pembuatan laporan pendaftaran dan keuangan diolah oleh sistem dan disimpan menggunakan database. Pada sistem yang diusulkan penulis, dalam pembuatan laporan - laporan tersebut hanya membutuhkan kertas hvs dan tinta saja untuk mencetak dokumen. Sehingga biya operasional sekolah akan menjadi lebih rendah

- Penulis merancang sistem dengan menggunakan hak akses sehingga setiap bagian yang memiliki otorisasi bisa masuk ke dalam sistem sesuai dengan tugas dan tanggung jawab masing - masing. Dan penulis mengusulkan adanya pembagian tugas untuk staf pendaftaran, staf keuangan, dan pengajar.

- Sistem yang diusulkan oleh penulis sudah menerapkan sistem database yang baik sehingga untuk menyimpan data - data yang penting 


\begin{abstract}
Pembuatan laporan pendaftaran dilakukan dengan menyalin dari buku pendaftaran dan di input ke dalam Microsoft Excel dan di laporkan kepada kepala sekolah.

Pembuatan laporan keuangan dengan merekap pada buku keuangan dan di hitung secara manual menggunakan kalkulator
\end{abstract}

\section{Pelayanan terhadap orang tua dan siswa membutuhkan waktu sekitar $\mathbf{1 5}$ menit. Sehingga membuat pelayanan pada orang tua serta siswa menjadi kurang terfasilitasi.}

dapat disesuaikan dengan masingmasing database.

Pembuatan laporan pendaftaran dan keuangan dengan mengecek data yang sudah tersimpan dalam database. Bila data tersebut telah lengkap maka sistem akan mengolah data tersebut menjadi sebuah laporan akhir yang akurat dan dilaporkan kepada kepala sekolah.

Pelayanan terhadap orang tua dan siswa membutuhkan waktu sekitar 7-10 menit. Sehingga membuat pelayanan pada orang tua dan siswa dapat terfasilitasi dengan baik dan akurat.

\section{SIMPULAN}

Kegiatan pengabdian masyarakat dapat membantu proses belajar mengajar, pelayanan administrasi dan pelaporan keuangan pusat kegiatan belajar masyarakat yang mana terintegrasi dengan baik, seperti sistem informasi keuangan dan sistem informasi administrasi PKBM Kegiatan ini juga memberikan kontribusi positif untuk menciptakan sebuah desain yang terarah dan terstruktur dengan baik. Maka dari itu, kegiatan ini dapat disimpulkan sebagai berikut :

1. Pusat kegiatan belajar mengajar sudah memiliki sistem informasi sekolah terpadu berbasis web yang baik dan akurat hal itu terlihat pada bagian pembahasan jurnal ini terdapat berbagai form-form untuk membantu pelaksanaan pengolahan data administrasi dan keuangan sehingga guru - guru dan staf PKBM dapat membuat laporan dengan baik, rapi, dan valid.

2. Pengolahan data administrasi tidak menggunakan sistem yang manual, pencatatannya rapi, dan diarsipkan sesuai sistem dengan menu yang sudah disiapkan di halaman belakang (back end) dengan kebutuhannya sehingga ketika dibutuhkan dapat diperoleh dengan cepat.

3. Guru-guru dan staf PKBM sudah dapat mengimplementasikan sebuah sistem ini dengan baik sesuai dengan knowledge yang telah ditransfer oleh tim abdimas.

\section{DAFTAR PUSTAKA}

Kamal, M. (2009). Pusat Kegiatan Belajar Masyarakat Dalam Pendidikan Luar Sekolah. Tersedia di: http:// http://pkbm-harapanbangsa.blogspot.co.id/2017/04/pusat-kegiatan-belajar-masyarakat-dalampendidikan-luar-sekolah.html, diakses pada 6 Mei 2018 Jam 06.30.

Kementerian Pendidikan dan Budaya. (2018). Data Perkembangan Kursus dan PKBM di Provinsi Jawa Barat.

Sahlan, A. dan Prasetyo, A. T. (2012). Desain pembelajaran berbasis pendidikan karakter. Yogyakarta: Ar-Ruzz Media.

Soelaman, J. (1992). Konsep Dasar Pendidikan Non Formal. Jakarta : Bumi Aksara. Undang-Undang Nomor 20 Tahun 2003 Tentang Pendidikan. 
Vol. 2, No. 2, July, 2021, pp. 192-206

e-ISSN:

2722-2004
Widayani, H. (2016). Analisis dan Perancangan Sistem Informasi Akuntansi Pelayanan Pasien Rawat Jalan dan Rawat Inap Pada Rumah Bersalin dan Klinik Gebang Medika. Tesis. Program Pascasarjana Universitas Gunadarma.
Implementation

of School

Information

System

Web-Based at

PKBM

Patrakomala
H. Widayani,

H. Rabbani,

N. Rosadi,

W. Megayanti. 